\title{
Until they have faces: the ethics of facial allograft transplantation
}

\author{
G J Agich, M Siemionow
}

Let us not forget those whose quality of life will be enhanced by this technique

$\mathrm{D}$ iscussion of facial allograft transplantation (FAT) for severe facial deformity, popularly known as facial transplantation, has tended to be one sided and sensationalistic. Media discussion has drawn heavily from film and science fiction where the procedure is used for cosmetic or nefarious purposes. The ethical commentary has reflected this sensationalistic orientation and approached the procedure with more than a little scepticism. As a result, the clinical need that the procedure is intended to address is mischaracterised. More importantly, the suffering of individuals with severe facial deformities is trivialised as negative social attitudes marginalise the right of these individuals to choose investigational procedures to improve their situation. In this paper, we discuss why FAT for facial deformity is ethically and surgically justified despite the negative reactions.

\section{BACKGROUND}

Facial transplantation emerged as a subject of public interest after UK surgeon Peter Butler announced his intention to perform the first procedure at the winter meeting of the British Association of Plastic Surgeons in December 2002. Media reports subsequently featured the procedure in a series of provocative articles ${ }^{1-5}$ that stressed the sensational nature of the surgery even identifying the first candidate for Butler's proposed surgery. ${ }^{6}$ These reports drew more from science fiction and film scenarios than clinical or scientific sources reflecting a "yuk" reaction to the procedure.

Disturbed at the sensationalistic coverage, the UK foundation, "Changing Faces" issued a press release in early 2003 that called upon the Royal College of Surgeons of England to create a moratorium on media coverage of the issue. Although unable to quell media discussion, the Royal College convened an advisory group that issued a report on facial transplantation in November 2003. ${ }^{8}$ Three months later, in February 2004, the National Consultative Ethics Committee for Health and Life Sciences of France also issued an opinion based on its review of a proposal by Dr Laurent

\section{Abstract}

The ethical discussion of facial allograft transplantation (FAT) for severe facial deformity, popularly known as facial transplantation, has been one sided and sensationalistic. It is based on film and fiction rather than science and clinical experience. Based on our experience in developing the first IRB approved protocol for FAT, we critically discuss the problems with this discussion, which overlooks the plight of individuals with severe facial deformities. We discuss why FAT for facial deformity is ethically and surgically justified despite its negative portrayal in the media.

Lantieri. ${ }^{9} \quad$ Both reports appropriately called for independent ethical scrutiny of proposals to undertake FAT for reconstruction of facial deformity as well as further research before such a procedure should be conducted.

In the USA, a team at the University of Louisville led by John Barker publicised its commitment to perform the first facial transplantation during 200304, announcing the submission of a protocol to the institutional review board (IRB) in May 2004..$^{10}$ At the Cleveland Clinic, a team led by Dr Maria Siemionow, who published the first research on successful transplantation of facial tissue in rats, ${ }^{11}{ }^{12}$ received IRB approval in October 2004.

Unwilling to join the race to be first, our team worked for over two years shunning media attention and concentrating, instead, on addressing the ethical and procedural concerns raised by the IRB. At this time, we think it is appropriate to offer our thoughts on the controversy over facial transplantation and the ethical foundation for this research. In doing so, we do not discuss or defend the protocol itself since these concerns have been addressed by others ${ }^{13}$; instead, we argue that the ethical discussion of this research should re-focus on the clinical need of patients with severe facial deformities.

\section{FACIAL IDENTITY: TRANSPLANT, TRANSFER, OR RECONSTRUCTION}

One obstacle to fairly evaluating the procedure is that the terminology and language associated with the procedure is problematic. Not only are the terms "facial transplantation" or "facial identity transfer" seriously misleading, but more accurate terms like "composite tissue allograft" or even "facial allograft transplantation" are also unclear regarding the extensiveness of the tissue transplanted. Composite tissue allografts (CTA) are transplants of organs composed of multiple tissue types that express different degrees of antigenicity. Examples include the human hand, larynx, abdominal wall, and knee joint. The facial skin allograft is an example of CTA transplantation that contains skin, subcutaneous tissues, scalp with hair and vessels, and nerves. The procedure could include transplantation of the full or partial tissue envelope along with underlying muscle and tissue or just the full or partial envelope. Transplantation of the skin envelope would not transfer the donor visage, but would result in a "face" comprised of features like skin color of the donor tissue and the recipient's own underlying facial structures and shape. Thus, transfer of any significant sense of facial identity is not a realistic goal. Instead, the ideal procedure would achieve an acceptable degree of expressivity, so that the result would be an organ able to communicate the patient's feelings and thoughts through facial expression.

As the French National Consultative Ethics Committee has pointed out, the face is not just a static mask, but an organ of expressivity. ${ }^{9}$ As an expressive organ, the face provides an affective and communicative presence to others. Despite the proliferation of electronic and other more impersonal forms of communication, face to face communication remains the paradigm of communication. Because of its expressive function, the face carries with it important symbolic, social, and psychological 
significance that cannot be overlooked. Portrayal of the procedure from the perspective of science fiction and film rather than science or clinical reality has distorted its therapeutic purpose. FAT for reconstruction of severe facial deformity is not a cosmetic procedure undertaken for vanity; neither is it a facial identity swap (as in the film Face/Off starring John Travolta and Nicholas Cage), nor does it extend the goal of transplantation from legitimate life saving to questionable life enhancement.

Worries about the misuse of the procedure overlook the fact that the candidates for the procedure are individuals with severe facial deformities that make their presentation in normal social settings extremely difficult, if not impossible. Diminished quality of life is the stark effect of their deformity, because the rest of us cannot accept them as they are. In this regard, we are as insensitive as the Victorians who regarded John Merrick, the so-called Elephant Man, as a curiosity focusing on his deformity rather than the sensitive person he was. ${ }^{14-16}$ A similar insensitivity seems to be at work in the media coverage of FAT and the ethical commentary that plays on the paradoxes of personal and social identity transfer rather than the clinical reality of severe facial deformity.

Like Merrick, the candidates for FAT suffer in an intolerant and insensitive world. Their profound wish is to recover a facial appearance that is within the normal range. They long for an agreeable face that will not elicit revulsion or avoidance. Improving patient welfare is a traditional obligation of medical ethics. ${ }^{17}$ One might analogise this procedure with other reconstructive procedures like surgery for cleft lip and palate, which are ethically justified insofar as they improve the child's quality of life and increase the potential for social interaction and normal development.

\section{THE CLINICAL REALITY}

Currently, reconstructive armamentarium for treatment of facial deformities due to severe trauma, burn injuries, gunshot wounds, or cancer, includes standard skin grafting, application of local flaps, tissue expansion, prefabrication, and free tissue transfers. ${ }^{18-24}$ Despite the efforts and introduction of microsurgical techniques, the results have been, at best, mediocre. The "mask-like" appearance, including skin discoloration, deforming contractures around the eyes, nose, mouth, and ears, make up the stigma of a deformed face that is visible even at a distance. At present, there is no effective way to hide or to change this appearance. Many patients seek repeated reconstructive attempts-as many as 30-50 surgical procedures. In the end, the results are usually not strikingly better leaving the patients with less hope and greater frustration.

The vascular anatomy of the face is well known, and adequate blood supply should be preserved for the survival of the transplanted facial allograft. Two successful cases of total face and scalp replantation have been reported. ${ }^{25}{ }^{26}$ In the first case, the replantation was based on multiple arterial and venous anastomosis (facial and superficial temporal vessels). ${ }^{25}$ However, the second case of face and scalp replantation was based only on a single artery and two veins (superficial temporal artery and veins). ${ }^{26}$ Both patients recovered with adequate animation of the facial muscles and intense hair growth on the scalp. Therefore, by preserving the terminal branches of the external carotid artery, facial and superficial temporal arteries, transplantation of the entire facial skin flap can be performed.

To cover an extensive facial deformity, the application of "face-like" tissue having the same colour, texture, pliability, and plasticity would be the best. Unlike the many sources available for skin grafting or free flap harvest from the patient's own body, no facial type of tissue is available once the face is severely damaged. The only option is a facial skin allograft taken from another human to replace the unappealing "facial mask" of deformity.

Calling such a procedure of facial resurfacing or coverage a "face transplant" is thus misleading. The human face is a unique organ composed of the bony framework covered with facial muscles and overlying skin. In patients with burns often only the skin component of the face is damaged; the bone, the muscles, and the eyes are intact and do not need replacement. Indeed, standard treatment protocols applied in burn units use only thin skin grafts to cover the face of burn patients. A transplant of the full facial organ, including underlying bones, muscles, and, perhaps, eyes, is far too radical an approach to correct the unappealing skin grafts. This point needs to be stressed, because attempts to transplant facial skin (and associated underlying subcutaneous tissues) for facial resurfacing of burned patients is far less than that envisioned in a Face/Off-type of full identity transfer. The underlying structures of the recipient would shape the resulting face as much as the overlying allograft tissue resulting in a composite result.

There are clearly defined risks associated with facial skin allograft transplantation. These are similar to the risks associated with solid organ transplants including the need for lifelong immunosuppression, increased risk for infection, metabolic disturbances (diabetes), development of malignancies (lymphoma), transplant rejection, or failure. The potential advantage of the facial tissue over kidney or heart transplantation is the option of autogenous skin regrafting in case of transplant failure followed by cessation of immunosuppression. In contrast, solid organ recipients either die when the graft is rejected (heart or liver) or are forced to resume dialysis in the case of kidney recipients. Currently, over 50 patients have received composite tissue transplants, including hand, larynx, abdominal wall, knee joint, nerve, tendon, muscle, and tongue. These patients decided to accept the risks of lifelong immunosuppression, because they could not cope with their deformity or disability.

The ethical commentary, however, has questioned whether improving quality of life can justify the risks of immunosuppression. This commentary, however, has not come to terms with the alternatives, which involves multiple burdensome reconstructive procedures or a life of social isolation. Critics assume that life saving is the only justified reason for undertaking the risks of immunosuppression. Although organ transplantation is often couched in the language of life saving, it is justifiably performed for quality of life improvement as well. ${ }^{27}$ For example, the use of living kidney donation for individuals for whom dialysis remains feasible is an accepted and growing practice.

Some critics have claimed that the loss of the graft would be devastating. Certainly, it would necessitate additional reconstructive procedures, but it would not be life threatening as some have claimed. ${ }^{28}$ The potential for graft rejection means that candidates must have appropriate tissue sites for regrafting should the allograft be rejected. If the graft was rejected, immunosuppression would be stopped eliminating its risks. Candidates for this procedure would have undergone multiple reconstructive procedures previously, so their ability to weigh the burden of further procedures should be solid.

Clearly, candidates for this procedure should undergo rigorous pretransplant assessment including psychiatric, psychosocial, and bioethical. The patients offered this innovative procedure should be fully informed of the risks and reasonable benefits that can be expected from participation in this trial. They and their family should receive counselling 
about the risks and challenges of being the first patients to undergo a procedure that has drawn so much media and public attention. Potential candidates for facial resurfacing by facial skin allograft transplantation should undergo a thorough screening process by team of multidisciplinary specialists under an IRB approved protocol as suggested by the Royal College of Surgeons $^{8}$ and National Consultative Committee. ${ }^{9}$ We believe our IRB approved protocol meets these standards and that severely disfigured patients who meet the entry criteria should have the choice whether to participate. Despite the risks, there is a significant chance that the one stage procedure of facial allograft resurfacing may successfully replace the need for multiple surgical attempts currently used to treat severely burned and disfigured patients.

\section{CONCLUSION}

Although the challenges of FAT for facial reconstruction are substantial, they do not support rejecting a trial of the procedure. Some of the opposition to a trial reflects the conviction that people suffering from severe deformity should simply endure their condition; their suffering is apparently not compelling. The patients, however, are not the problem. The insensitivity of society towards these deformed individuals has also distorted the discussion of this procedure. Until "normal" society is able to look beyond the public face of deformity to the face that reveals the patient's inner worth and dignity, the need for reconstructive surgery will remain. Attempting to advance the frontiers of treatment by undertaking a trial of FAT represents not only a scientifically justified step in the surgical effort to ameliorate the suffering of these individuals, but an ethically justified response to the lack of acceptable options for these patients. The sad reality is that until they have faces, society does not seem ready to countenance these patients.

J Med Ethics 2005;31:707-709.

doi: 10.1136/jme.2005.011841

Authors' affiliations

Authors' affiliations

G J Agich, Department of Bioethics, Transplant Center, Cleveland Clinic Foundation,

Cleveland, $\mathrm{OH}$, USA

M Siemionow, Department of Plastic Surgery, Cleveland Clinic Foundation, Cleveland, $\mathrm{OH}$, USA

Correspondence to: G J Agich, Department of Bioethics, Transplant Center, Cleveland Clinic Foundation, 9500 Euclid Avenue, Cleveland, OH 44195, USA; agichg@ccf.org

\section{REFERENCES}

1 Kirby R. Face switching procedures could be the next big thing. The Salt Lake Tribune 22 January, 2004

2 Clark J. Face transplants technically possible, but "very hazardous". Can Med Assoc J 2004; 170:323.

3 In your face: if the idea of a hand transplant seems hard to take, just wait. New Scientist 3 October 1998;160:3

4 American Society of Plastic Surgeons. Science fiction of face transplants may be closer than you think; Reconstructive plastic surgeons perform miracle transplants now. American Society of Plastic Surgeons, May 2004. Available at www.plasticsurgery.org/news_room/ press_releases/Science-Fiction-of-FaceTransplants.cfmRef (accessed 17 May 2005).

5 LaFee S. Trading faces: proposed transplants promise new outlook but at unseen cost. San Diego Union Tribune 10 February, 2004.

6 Betferhumans Staff. Face transplant planned for Irish girl. Betterhumans. com 6 March, 2003.

7 Caplan A, Katz D. About face. Hastings Cent Rep 2003;33:8.

8 Working Party on Facial Transplantation of the Royal College of Surgeons of England. Facial Transplantation: Working Party Report. London, UK: Royal College of Surgeons of England, 2003.

9 Comité Consultatif National d'Ethique pour les sciences de la vie et de la santé. L'allotransplantation de tissu composite (ATC) au niveau de la face (Greffe totale ou partielle d'un visage). Paris: Comité consultative national d'éthique pour les sciences de la vie et de la santé; 2004, Report No.: Opinion 82.

10 CNN. Face transplants inch toward reality: University of Louisville doctors to seek ethics review of surgery. CNN, 2004. Available at www.cnn.com/2004/TECH/science/05/26/ face.transplant/index.html (accessed 17 May 2005).

11 Siemionow M, Gozel-Ulusal B, Engin UA, et al. Functional tolerance following face transplantation in the rat. Transplantation 2003;75: 1607-9.

12 Ulusal BG, Ulusal AE, Ozmen S, et al. A new composite facial and scalp transplantation model in rats. Plast Reconstr Surg 2003;1 12:1302-11.

13 Wiggins OP, Barker JH, Martinez S, et al. On the ethics of facial transplantation research. Am J Bioethics 2004;4:1-12.

14 Elephant Man and Medical Anomalies. Available at www.zoraskingdom. freeserve.co.uk/ 31 December 2000 (cited 9 September 2004) (accessed 17 May 2005)

15 John Merrick Tribute Website www.jsitton.pwp.blueyonder.co.uk/ elephantman/elephant_man.htm 15 May 2004 (cited 9 September 2004) (accessed 17 May 2005).

16 Howell M, Ford P. The True History of the Elephant Man. London: Allison \& Busby, 2001

17 Pellegrino ED, Thomasma DC. For the Patient's Good: The Restoration of Beneficience in Health Care. New York: Oxford University Press, 1988.

18 Boyd JB. Tissue expansion in reconstruction. South Med J 1987:80:430-2.

19 Erol OO. The transformation of a free skin graft into a vascularized pedicled flap. Plast Reconstr Surg 1976;58:470-7.

20 Kawashima T, Yamada A, Ueda K, et al. Tissue expansion in facial reconstruction. Plast Reconstr Surg 1994;94:944-50

21 Latifoglu O, Ayhan S, Atabay K. Total face reconstruction: skin graft versus free flap. Plast Reconstr Surg 1999;103:1076-8.

22 McIndoe AH. Total reconstruction of the burned face. The Bradshaw Lecture 1958. Br J Plast Surg 1983:36:410-20.

23 Pribaz JJ, Fine N, Orgill DP. Flap prefabrication in the head and neck: a 10-year experience. Plast Reconstr Surg 1999; 103:808-20.

24 Teot L, Cherenfant E, Otman S, et al. Prefabricated vascularised supraclavicular flaps for face resurfacing after postburns scarring. Lancet 2000;355: 1695-6

25 Thomas A, Obed V, Murarka A, et al. Total face and scalp replantation. Plast Reconstr Surg 1998; 102:2085-7.

26 Wilhelmi BJ, Kang RH, Movassaghi K, et al. First successful replantation of face and scalp with single-artery repair: model for face and scalp transplantation. Ann Plast Surg 2003;50:535-40.

27 Agich GJ. Extension of organ transplantation: some ethical considerations. Mt Sinai J Med 2003;70:141-7.

28 Allen W. Louisville doctors studying face transplants weigh ethical issues. The CourierJournal 16 November, 2003. 